\title{
Diazotrophic community and associated dinitrogen fixation within the temperate coral Oculina patagonica
}

\author{
Bednarz Vanessa N. 1, ${ }^{\star}$, Van De Water Jeroen A. J. M. 1, Rabouille Sophie ${ }^{2,3}$, Maguer Jean-Francois ${ }^{4}$, \\ Grover Renaud ${ }^{1}$, Ferrier-Pages Christine ${ }^{1}$
}

${ }^{1}$ Ctr Sci Monaco, Marine Dept, 8 Quai Antoine ler, MC-98000 Monaco, Monaco.

2 UPMC Univ Paris 06, Sorbonne Univ, UMR 7093, LOV,Observ Oceanol, F-06230 Villefranche Sur

Mer, France.

${ }^{3}$ CNRS, UMR 7093, LOV, Observ Oceanol, F-06230 Villefranche Sur Mer, France.

4 Inst Univ Europeen Mer, LEMAR, UMR 6539, UBO,CNRS,IRD, PI Nicolas Copernic, F-29280

Plouzane, France.

* Corresponding author : Vanessa N. Bednarz, email address : vbednarz@centrescientifique.mc

\begin{abstract}
:
Dinitrogen (N-2) fixing bacteria (diazotrophs) are an important source of new nitrogen in oligotrophic environments and represent stable members of the microbiome in tropical corals, while information on corals from temperate oligotrophic regions is lacking. Therefore, this study provides new insights into the diversity and activity of diazotrophs associated with the temperate coral Oculina patagonica from the Mediterranean Sea by combining metabarcoding sequencing of amplicons of both the 16S rRNA and nifH genes and $\mathrm{N}-15(2)$ stable isotope tracer analysis to assess diazotroph-derived nitrogen (DDN) assimilation by the coral. Results show that the diazotrophic community of $O$. patagonica is dominated by autotrophic bacteria (i.e. Cyanobacteria and Chlorobia). The majority of DDN was assimilated into the tissue and skeletal matrix, and DDN assimilation significantly increased in bleached corals. Thus, diazotrophs may constitute an additional nitrogen source for the coral host, when nutrient exchange with Symbiodinium is disrupted (e.g. bleaching) and external food supply is limited (e.g. oligotrophic summer season). Furthermore, we hypothesize that DDN can facilitate the fast proliferation of endolithic algae, which provide an alternative carbon source for bleached O. patagonica. Overall, O. patagonica could serve as a good model for investigating the importance of diazotrophs in coral recovery from bleaching.
\end{abstract}




\section{Introduction}

Biological atmospheric dinitrogen $\left(\mathrm{N}_{2}\right)$ fixation by specialized prokaryotes

(diazotrophs) represents a globally important biogeochemical process for both terrestrial and marine ecosystems. Most parts of the world's open oceans are depleted in inorganic nitrogen $(\mathrm{N})$ at the surface where $\mathrm{N}_{2}$ fixation by pelagic free-living diazotrophs produces significant amounts of bioavailable N needed for oceanic primary production (Capone et al., 1997; Zehr et al., 2001; Montoya et al., 2004). Benthic $\mathrm{N}_{2}$ fixation is particularly high on tropical coral reefs as diazotrophs form associations with various organisms such as clams, sponges, corals, ascidians and seagrasses (Fiore et al., 2010; Cardini et al., 2014; Cardini, Bednarz, et al., 2016; Benavides et al., 2017).

Scleractinian corals represent the main primary producers on tropical coral reefs due to their symbiosis with photosynthetic dinoflagellates of the genus Symbiodinium (Dubinsky and Jokiel, 1994; Stambler, 2011). In addition, corals live in close association with a diverse community of other microorganisms, including diazotrophs, located in the animal tissue, coral mucus layer and skeleton (reviewed in Benavides et al., 2017). Although the abundance, localisation, diversity and role of diazotrophs in the coral holobiont are not yet well defined, experiments using ${ }^{15} \mathrm{~N}_{2}$ tracers showed for the tropical coral Stylophora pistillata a significant 
${ }^{15} \mathrm{~N}$ enrichment in Symbiodinium, suggesting that diazotrophs are a source of $\mathrm{N}$ for the algae (Benavides et al., 2016). Increased $\mathrm{N}_{2}$ fixation by diazotrophs, and increased transfer of diazotrophically-derived nitrogen (DDN) to Symbiodinium particularly occurs when external nutrient availability is low or during bleaching (Cardini et al., 2015; Cardini, van Hoytema, et al., 2016; Bednarz et al., 2017). Bleaching, the disruption of the mutualistic association between the coral host and Symbiodinium due to high temperature anomalies, represents a major threat to coral reefs worldwide giving the globally rising sea surface temperatures. The loss of Symbiodinium largely reduces the energy supplied to the coral host, leading to a decrease in protein and lipid contents, growth rates, calcification, reproduction and in the worst case to coral mortality (Plass-Johnson et al., 2015). Mechanistic models on the role of diazotrophs for coral holobiont functioning suggested that DDN either 1) benefits corals to better withstand and recover from bleaching events by providing $\mathrm{N}$ essential for cell repair mechanisms, to the build-up of photosynthetic and photoprotective pigments and to sustain photosynthesis rates (Cardini et al., 2015; Cardini, van Hoytema, et al., 2016; Bednarz et al., 2017), or 2) triggers bleaching by generating an imbalanced nutrient supply leading to phosphorus (P) starvation of Symbiodinium (Pogoreutz et al., 2017). All together, these contrasting models highlight the need for more studies on the diversity and activity of diazotrophs within coral holobionts under varying environmental conditions.

Temperate corals are good models to study the interactions between the coral host and Symbiodinium and/or bacterial symbionts as they experience strong seasonal variations in environmental conditions (Pedrós-Alió et al., 1999; D'Ortenzio and Ribera d'Alcalà, 2009). The temperate coral Oculina patagonica (Scleractinia, Oculinidae) represents one of the most common scleractinian coral species in the Mediterranean Sea. It has a broad tolerance to a range of seawater trophic states (ultra-oligotrophic in the eastern south basin to mesotrophic in the western north basin) and seawater temperatures (from $12^{\circ} \mathrm{C}$ in winter up to $31^{\circ} \mathrm{C}$ in 
summer, from North to South) (Shenkar et al., 2005; Rubio-Portillo, Vázquez-Luis, et al., 2014). Annual bleaching of this species has been reported every summer since 1993 along the Israeli coast, either through Vibrio infection or when temperature rises to $31^{\circ} \mathrm{C}$ (Ainsworth $e t$ al., 2008; Mills et al., 2013; Rubio-Portillo, Yarza, et al., 2014). In the Western Mediterranean Sea, summer temperature is often too low to induce bleaching, although partial bleaching can be observed when the temperature exceptionally increases to $\geq 28^{\circ} \mathrm{C}$ (Kushmaro et al., 1996, 1998; Rubio-Portillo, Vázquez-Luis, et al., 2014). O. patagonica colonies often fully recover from annual bleaching events once the temperature stress subsides (Shenkar et al., 2005; Rubio-Portillo, Vázquez-Luis, et al., 2014). Tissue regeneration of $O$. patagonica is among the highest reported for a coral species, particularly at high latitudes (Henry and Hart, 2005). The required energy allocated to tissue recovery can derive from different sources. At meso- to eutrophic sites of the north western basin, the high food availability in the water column was suggested to provide the energy to quickly regenerate bleached or lost tissue (Rubio-Portillo, Vázquez-Luis, et al., 2014). Under the oligotrophic conditions of the Eastern south basin, it was demonstrated, using isotopically labelled bicarbonate, that bleached portions of $O$. patagonica colonies benefit from two alternative photosynthate sources, that are translocated 1) intra-colonially from non-bleached tissue portions (Fine et al., 2002), and 2) from the skeletal endolithic community (Fine and Loya, 2002). Both, the endolithic and the tissue-associated bacterial communities of $O$. patagonica contain cyanobacteria (Ainsworth et al., 2008; Rubio-Portillo et al., 2016) that may be able to transfer not only photosynthates as demonstrated, but also DDN and supply the coral host with beneficial carbon (C) and $\mathrm{N}$ sources during bleaching. While we have recently observed that coral-associated diazotrophs may function as additional $\mathrm{N}$ source for tropical corals, particularly during oligotrophic conditions or bleaching, information on corals from temperate regions is lacking. 
For this purpose, specimens of the temperate coral species $O$. patagonica were freshly collected from the northwest Mediterranean Sea at an ambient seawater temperature of $16^{\circ} \mathrm{C}$ to identify the in situ coral-associated overall bacterial and diazotrophic community using $16 \mathrm{~S}$ rRNA and nifH gene sequencing, respectively. A second set of coral specimens was exposed to ambient $\left(16^{\circ} \mathrm{C}\right)$ and elevated $\left(28^{\circ} \mathrm{C}\right)$ temperature conditions to thermally induce bleaching in the latter and to quantify DDN assimilation into the different coral compartments (i.e. mucus, Symbiodinium, tissue and endoliths) of non-bleached and bleached corals using ${ }^{15} \mathrm{~N}_{2}$ tracer experiments. The specific aims were 1) to describe the diazotrophic community structure associated with the temperate coral $O$. patagonica and compare it to the community associated with tropical corals, 2) to quantify DDN assimilation into the different coral compartments of $O$. patagonica and 3) to compare the compartment-specific DDN assimilation of non-bleached and bleached colonies. The overall aim was to extend our present understanding of coral-associated $\mathrm{N}_{2}$ fixation to temperate corals.

\section{Results}

\section{In situ bacterial and diazotrophic communities associated with healthy $O$. patagonica}

Analyses of the alpha diversity and the unweighted UniFrac beta diversity metric of the overall bacterial communities showed significant differences in the operational taxonomic units (OTUs) that were retrieved from the mucus of $O$. patagonica and the seawater (unweighted UniFrac $p=0.02$ ). In contrast, analysis of the weighted UniFrac beta diversity metric, which takes the abundance of the observed taxa into account, did not show statistical differences between mucus and seawater (Figure 1; weighted UniFrac $p=0.154$ ). The overlap observed in the mucus and seawater microbial communities could be expected, as the coral mucus was diluted in seawater before collection. Differences in the alpha diversity and the 
unweighted UniFrac were also observed for the tissue of $O$. patagonica and both the coral mucus and the surrounding seawater (Supplementary Table S1, S2). Similarly, analysis of the weighted UniFrac beta diversity metric showed that the microbial community structures in the tissue were also highly divergent from the mucus and seawater $(\mathrm{p}<0.005 ;$ Fig. 1A). The tissue-associated prokaryotic community was dominated by Cyanobacteria (20\%) and Alphaproteobacteria belonging to the orders Rhizobiales (6.6\%), Rhodospirillales (11.7\%) and Rhodobacterales $(9.0 \%)$, all known to contain putative diazotrophic species, in addition to numerous Bacteroidetes and Planctomycetes, and relatively few Chlorobi and Gammaproteobacteria (Fig. 1A). In contrast, the mucus contained a very low relative abundance of potentially diazotrophic Cyanobacteria and Alphaproteobacteria, but a higher proportion of Gammaproteobacteria, Bacteroidetes and non-diazotrophic Alphaproteobacteria (SAR11 and Sphingomonadales) (Fig. 1A). The seawater was dominated by Oceanospirillales (Gammaproteobacteria) and SAR11.

Analysis of the diazotrophic community based on nifH gene amplicon sequencing showed no significant differences in alpha diversity between the tissue and mucus compartment ( $p=0.91$; Supplementary Table S1, S2), while beta diversity revealed significant differences $(p=0.04)$. No nifH genes were found in the seawater. Clustering of nifH gene amplicon sequences at 95\% similarity identified 24 novel nifH oligotypes. Using phylogenetic analyses on the peptide sequence level, the oligotypes were assigned to different taxa showing a taxonomically diverse community of $\mathrm{N}_{2}$ fixing bacteria (Fig. 1B, Fig. 2). Interestingly, the diazotrophs found in O. patagonica showed some degree of relatedness to diazotrophs previously identified in tropical scleractinian corals (Supplementary Fig. S1). Significant differences in the composition of the diazotrophic community were observed between coral tissue and mucus. Among the identified diazotrophs, the most abundant tissueassociated bacteria belonged to the Cyanobacteria, Chlorobia and various 
Alphaproteobacteria, while the mucus diazotrophic community consisted primarily of Gammaproteobacteria, particularly those that likely belong to the order Vibrionales (Fig. 1B).

\section{$\mathrm{N}_{2}$ fixation and key physiological parameters associated with healthy and bleached $O$. patagonica}

Incubating healthy $O$. patagonica corals over $24 \mathrm{~h}$ in ${ }^{15} \mathrm{~N}_{2}$-enriched seawater resulted in a significant ${ }^{15} \mathrm{~N}$ enrichment in the tissue, Symbiodinium and skeleton as compared to the control incubations, to which no ${ }^{15} \mathrm{~N}$ tracer was added (Supplementary Table S3). No ${ }^{15} \mathrm{~N}$ excess enrichment was detected in the mucus compartment. Total DDN assimilation by healthy $O$. patagonica averaged $4.34 \pm 0.81 \mathrm{ng} \mathrm{N}$ normalized per $\mathrm{cm}^{2}$ skeletal surface area $\mathrm{h}^{-1}$ (Fig. 3) and $6.06 \pm 1.01 \mathrm{ng} \mathrm{N}$ normalized per $\mathrm{g}^{-1}$ total dry weight $\mathrm{h}^{-1}$ (Supplementary Fig. S2). Thereof, the majority of DDN was assimilated into the animal tissue (62\%) and skeleton (33\%), while only a minor fraction was present within Symbiodinium (7\%). Total DDN assimilation significantly increased in bleached $O$. patagonica corals $\left(11.30 \pm 0.74 \mathrm{ng} \mathrm{N} \mathrm{cm}{ }^{-2}\right.$ coral surface area $\mathrm{h}^{-1}$ or $13.67 \pm 1.89 \mathrm{ng} \mathrm{N}$ normalized per $\mathrm{g}^{1}$ total dry weight $\mathrm{h}^{-1}$ ) as compared to healthy corals (Supplementary Table S4). The difference was attributed to a significantly increased DDN assimilation into the tissue and skeleton. The tissue of bleached corals also assimilated more DDN when normalized to the tissue dry weight, while Symbiodinium and the skeleton assimilated similar amounts of DDN per compartment biomass at both temperature treatments (Fig. 4).

The Symbiodinium density significantly decreased in bleached corals, while gross photosynthesis $\left(P_{\mathrm{g}}\right)$ rates and the photosynthetic efficiency of photosystem II $(F v / F m)$ remained constant in both healthy and bleached corals suggesting that the latter was able to maintain its photosynthetic $\mathrm{C}$ input (Table 1). Also, the respiration rate $(R)$ and heterotrophic 
grazing on Artemia salina nauplii were stable in both treatments. The calculated daily $\mathrm{N}$ input from grazing on Artemia salina nauplii reached $13.1 \pm 2.8$ and $13.7 \pm 1.9 \mu \mathrm{g} \mathrm{N} \mathrm{cm}^{-2} \mathrm{~d}^{-1}$ in healthy and bleached corals, respectively. This represents a 130-fold (for healthy corals) and 50-fold (for bleached corals) higher $\mathrm{N}$ input as compared to the assimilation of DDN.

\section{Discussion}

\section{The diazotrophic community associated with healthy $O$. patagonica}

Corals are known to harbour a diverse diazotrophic community, but studies so far are limited to few tropical coral species. Here, we provide a first description of the diazotrophic community associated with the temperate coral $O$. patagonica from the Mediterranean Sea. The overall bacterial communities showed a strong compartmentalization between the tissue and mucus microhabitats. This has been previously described for O. patagonica, whereof tissue-associated bacteria are overall more abundant and diverse compared to the mucus (Koren and Rosenberg, 2006; Rubio-Portillo et al., 2016). Here, the most dominant bacterial groups within the tissue belonged to Cyanobacteria as well as Alphaproteobacteria of the orders Rhizobiales, Rhodospirillales and Rhodobacterales, which are known to contain putative diazotrophs associated with tropical corals (Lema et al., 2012; Lesser et al., 2018), and thus may also play a key role for $\mathrm{N}_{2}$ fixation within $O$. patagonica.

Accordingly, all nifH sequences recovered from $O$. patagonica were closely affiliated with known bacterial taxa in Clusters I and III (true nifH) and showed, similar to the overall bacterial community, a strong compartmentalization between tissue and mucus. Comparison of $O$. patagonica specific nifH sequences with those previously recovered from tropical corals, reveals phylogenetic similarities for the majority of nifH sequences (Olson et al., 2009; 
Lema et al., 2012; Lesser et al., 2018). This indicates that certain diazotrophic taxa could be generalist symbionts displaying a widespread geographical occurrence to form associations with both temperate and tropical coral hosts. However, compositional differences appear between $O$. patagonica and tropical corals with respect to the relative abundance of specific diazotrophic groups. Here, autotrophic diazotrophs consisting of Cyanobacteria and Chlorobia (green sulfur bacteria) dominated the tissue community, while the mucus community consisted mainly of heterotrophic Gammaproteobacteria (particularly Vibrios). The tissuerather than the mucus-associated diazotrophic community structure has been previously described as coral species-specific and stable over space and time (Lema et al., 2012; Lema, Willis, et al., 2014). In tropical corals, Cyanobacteria and Chlorobia are also common microbiome members, but the diazotrophic community in the tissue is more often dominated by heterotrophic Alphaproteobacteria (i.e. Rhizobiales, Rhodospirillales, Rhodobacterales) and Gammaproteobacteria (i.e. Vibrionales) (Olson et al., 2009; Lema et al., 2012; Olson and Lesser, 2013; Lema, Willis, et al., 2014; Santos et al., 2014; Yang et al., 2015; Lesser et al., 2018). Only one study identified Chlorobia to clearly dominate (>80\%) the diazotrophic community in a tropical coral (Yang et al., 2015), which, besides $\mathrm{N}_{2}$ fixation, potentially reveals additional ecological functions for the coral host such as anoxygenic photosynthesis, C fixation and sulfur oxidation (Yang et al., 2016; Cai et al., 2017). The high relative abundance of potentially autotrophic as compared to heterotrophic diazotrophs in $O$. patagonica suggests that these bacteria may provide, besides DDN, also fixed $\mathrm{C}$ to the coral host. In the open ocean, unicellular, diazotrophic cyanobacteria are known to exude large amounts of $\mathrm{C}$ to the oligotrophic environment (Rabouille et al., 2017), and symbiotic autotrophic cyanobacteria within sponges supply a significant amount of fixed $\mathrm{C}$ to their host (Erwin and Thacker, 2008). Similarly, coral-associated cyanobacteria may constitute an alternative $\mathrm{C}$ source for the coral host that could be beneficial when the supply from 
Symbiodinium is disrupted. Furthermore, $\mathrm{N}_{2}$ fixation is an energy-costly process, and heterotrophic, coral-associated diazotrophs are likely $\mathrm{C}$ limited since their activity can be stimulated by external enrichment in organic C (Pogoreutz et al., 2017). Thus, if the autotrophic diazotrophs in $O$. patagonica are actively fixing $\mathrm{N}_{2}$, they likely have a lower reliance on external $\mathrm{C}$ sources by self-sustaining the required energy for $\mathrm{N}_{2}$ fixation. Overall, the relative high abundance of diazotrophic Cyanobacteria in $O$. patagonica suggests that they may be a constant and important component within this coral holobiont. This contrasts observations in the planktonic Mediterranean ecosystem, where blooms of planktonic $\mathrm{N}_{2}$ fixing cyanobacteria appear rather sporadic (Le Moal and Biegala, 2009) being triggered by elevated temperatures and dust deposition events that bring additional nutrients (Ridame $e t$ al., 2011; Sabeur et al., 2016). In a sponge-diazotroph symbiosis it was found, among the diverse diazotrophic community of Proteobacteria and Cyanobacteria, that the expression of nifH genes was solely affiliated with Cyanobacteria (Mohamed et al., 2008). It should be noted that our study is limited to a qualitative description of the diazotrophic community, and we cannot draw conclusions about the absolute abundance and activity of specific diazotrophic members. Therefore, a combined metagenomics and metatranscriptomics study investigating the taxonomic origin and number of nifH transcripts in $O$. patagonica will be necessary in order to verify whether Cyanobacteria and Chlorobia represent indeed key diazotrophs that actively fix $\mathrm{N}_{2}$ and whether their nifH gene expression is affected by changing environmental conditions.

\section{$\mathrm{N}_{2}$ fixation activity associated with healthy $O$. patagonica}

Several previous ${ }^{15} \mathrm{~N}_{2}$ tracer studies assessed coral-associated $\mathrm{N}_{2}$ fixation within the mucus, Symbiodinium and tissue compartment of corals, but mainly focused on tropical 
species except for one study including Lophelia pertusa, a Symbiodinium-free cold-water coral (Middelburg et al., 2015; Benavides et al., 2016; Bednarz et al., 2017; Sangsawang et al., 2017; Lesser et al., 2018). Here, we report $\mathrm{N}_{2}$ fixation activity within a temperate coral species. We accounted for the assimilation of DDN into all different coral compartments, including mucus, Symbiodinium, tissue and endoliths, allowing us to estimate the total amount of DDN potentially available to the $\mathrm{N}$ budget of the coral holobiont. Total DDN assimilation averaged $4.34 \pm 0.81 \mathrm{ng} \mathrm{N} \mathrm{cm}^{-2} \mathrm{~h}^{-1}$ (or 6.06 $\pm 1.01 \mathrm{ng} \mathrm{N} \mathrm{g}^{-1}$ dry weight $\mathrm{h}^{-1}$ ) in healthy $O$. patagonica corals. Thereof, the majority was detected within the host tissue (62\%) and endoliths (33\%), with only a minor proportion present in Symbiodinium (7\%) and mucus $(0 \%)$. Previous ${ }^{15} \mathrm{~N}_{2}$ tracer studies on tropical corals reported similar DDN assimilation rates into the tissue compartment of S. pistillata $\left(0.97-3.58 \mathrm{ng} \mathrm{N} \mathrm{cm}^{-2} \mathrm{~h}^{-1}\right.$; Bednarz et al., 2017) and Porites lutea (2.47 $\pm 0.78 \mathrm{ng} \mathrm{N} \mathrm{cm}^{-2} \mathrm{~h}^{-1}$; Sangsawang et al., 2017). Although two other studies on S. pistillata traced $>95 \%$ of DDN within Symbiodinium and suggested this compartment as the primary site for DDN (i.e. ammonium) uptake (Benavides et al., 2016; Lesser et al., 2017), the coral host is also capable of assimilating ammonium (Pernice et al., 2012). Also, the presence of active diazotrophs within L. pertusa and Symbiodinium-free tropical coral larvae suggests that these bacteria form associations directly with the coral host independently of the symbiosis with Symbiodinium (Lema, Bourne, et al., 2014; Middelburg et al., 2015). The observed high DDN assimilation into the tissue of $O$. patagonica is possibly linked to the overall higher abundance of bacteria in the tissue as compared to the coral mucus (Koren and Rosenberg, 2006). In addition, it might result from an efficient transfer of DDN recently assimilated into other compartments, such as the skeletal matrix, since the ${ }^{15} \mathrm{~N}_{2}$ tracer approach identifies the fate of DDN rather than the place of $\mathrm{N}_{2}$ fixation. It should be noted also that we cannot explicitly tell, whether DDN is retained by diazotrophic cells for their own metabolism, or translocated to the coral host. Given that endosymbiotic diazotrophs 
within diatoms rapidly transfer $97 \%$ to their symbiotic partner (Foster et al., 2011) and free living diazotrophs release most of their recently fixed $\mathrm{N}$ into their environment (Glibert and Bronk, 1994; Mulholland and Bernhardt, 2005; Dron et al., 2012, 2013), we can reasonably assume that most of the DDN is translocated to the coral host. A significant transfer of $\mathrm{N}$ from bacterial associates to coral larvae has been demonstrated previously (Ceh et al., 2013), but whether this holds true for coral adults remains to be investigated. Therefore, future studies should aim to visualize the translocation of DDN from diazotrophs to coral cells as well as the transfer between the different coral compartments, which could be achieved using highresolution nanoscale secondary ion mass spectrometry (NanoSIMS).

The skeleton contained the second highest amount of DDN in O. patagonica, which may have been derived from an active community of endolithic diazotrophs. Although we did not identify the diazotrophic community associated with the skeleton, putative $\mathrm{N}_{2}$ fixing Cyanobacteria are known as common members of the endolithic community in $O$. patagonica (Fine and Loya, 2002; Ainsworth et al., 2008). Also, high excretion rates of ammonium (i.e. the end product of $\mathrm{N}_{2}$ fixation) have been observed from the endolithic community (Ferrer and Szmant, 1988; Szmant et al., 1990) and may constitute the fixed $\mathrm{N}_{2}$ compounds released by endolithic diazotrophs. Only one previous study on tropical corals (Porites lutea) differentiated between DDN assimilation into the tissue and by endoliths (Sangsawang et al., 2017). DDN assimilation into the tissue was similar between $P$. lutea and $O$. patagonica, while assimilation by endoliths was 10-times lower in the former. The substantially higher endolithic $\mathrm{N}_{2}$ fixation in $O$. patagonica suggests that it may constitute an alternative and nonnegligible $\mathrm{N}$ source, if DDN is subsequently translocated and assimilated by the coral host, as previously observed with $\mathrm{C}$ compounds from endolithic photosynthates (Fine and Loya, 2002). . 


\section{Potential role of diazotrophs in the bleached coral $O$. patagonica}

Total DDN assimilation was 2 to 3-fold higher in bleached as compared to healthy $O$. patagonica corals, mainly due to an increased assimilation into the tissue and by endoliths. Elevated $\mathrm{N}_{2}$ fixation also occurs in tropical corals during thermal-stress and bleaching (Cardini, van Hoytema, et al., 2016; Bednarz et al., 2017; Pogoreutz et al., 2017). Two hypotheses have been proposed about the impact of increased $\mathrm{N}_{2}$ fixation in corals: it might either increase their bleaching resilience (Santos et al., 2014; Cardini, van Hoytema, et al., 2016), or, induce bleaching by releasing Symbiodinium from its N-limited state (imbalanced $\mathrm{N}: \mathrm{P}$ ratio; Pogoreutz et al., 2017). In our experiment, the increased diazotrophic activity was not able to mitigate bleaching, since $O$. patagonica corals bleached at $28^{\circ} \mathrm{C}$ as indicated by a $60 \%$ reduction in Symbiodinium density. Despite bleaching, photosynthetic efficiencies and photosynthesis rates remained stable indicating that the photosystem II was not impaired by heat stress which is in line with previous reports (Rodolfo-Metalpa et al., 2006, 2008, 2014). This may possibly result from an increased photosynthetic and photoprotective pigment content for which DDN may be beneficial (Béraud et al., 2013). At the same time, bleaching of $O$. patagonica was likely not the result of a diazotroph-induced imbalanced N:P ratio in the coral tissue. Corals were fed twice a week with Artemia salina nauplii, providing them an organic source of both $\mathrm{N}$ and $\mathrm{P}$ (Wijgerde et al., 2011). In addition, the amount of DDN assimilated per gram Symbiodinium dry weight was similar between the two temperature treatments demonstrating that the DDN supply to Symbiodinium was not impacted under elevated temperature and/or during bleaching. Regardless of the role of diazotrophs during the onset of bleaching (whether beneficial or detrimental), it is unlikely that $O$. patagonica maintains potentially detrimental diazotrophs after symbiosis breakdown, considering the high bleaching recovery capacity of this coral species (Henry and Hart, 2005; Serrano et al., 2017) together with the increased assimilation of DDN into the tissue and skeleton. We thus 
hypothesize that diazotrophs could facilitate the survival of $O$. patagonica during bleaching and/or subsequent recovery.

In order to obtain a representative in situ contribution of DDN to the coral's total $\mathrm{N}$ incorporation, we considered $\mathrm{N}$ uptake rates from different sources previously determined for O. patagonica at in situ relevant concentrations (Grover et al., 2002; Tremblay et al., 2011). DDN assimilation is rather low compared to $\mathrm{N}$ derived from heterotrophic feeding on microzooplankton and pico- and nanoplankton, but can be in the same order of magnitude as the $\mathrm{N}$ supply from detrital particulate organic matter and dissolved inorganic $\mathrm{N}$ (Table 2). Despite this low contribution, diazotrophs may insure a rather constant provision of $\mathrm{N}$, since microzooplankton availability can be episodic and particularly low during the oligotrophic summer season (Coma et al., 2000; Coma and Ribes, 2003; Coma et al., 1994). Furthermore, bleached corals may not necessarily rely on additional $\mathrm{N}$ but require extra $\mathrm{C}$ input. The expulsion of Symbiodinium can be beneficial for corals exposed to thermal stress in order to prevent oxidative stress and tissue necrosis (Rodolfo-Metalpa et al., 2014), but the reduced flux of fixed C from Symbiodinium to the host can shift the nutritional status from $\mathrm{N}$ to $\mathrm{C}$ limitation (Cunning et al., 2017). Thus, bleached corals need to exploit alternative C sources to compensate this energy deficit and sustain further net growth. This can be achieved via increased heterotrophic feeding on organic $\mathrm{C}$ from the surrounding seawater, although the availability of organic $\mathrm{C}$ is rather limiting in many reefs as well as in the oligotrophic Mediterranean Sea. It has been shown on some coral species, including O. patagonica, that an endolithic algal community quickly develops in bleached corals providing an alternative photosynthetic energy source to the coral host when supply of photoassimilates by Symbiodinium is impaired (Fine and Loya, 2002; Sangsawang et al., 2017). Although we did not quantify the abundance of endolithic algae in bleached $O$. patagonica, their density possibly increased as indicated by the stable photosynthesis rates despite reduced 
Symbiodinium density. Given the importance of $\mathrm{N}$ in cell maintenance, growth and functioning, an increased DDN supply may provide an important $\mathrm{N}$ source for photosynthesizing endolithic algae to quickly proliferate in bleached $O$. patagonica corals (Fig. 5). All together, DDN may help O. patagonica to overcome C limitation, thereby possibly contributing to its high recovery potential from annual bleaching events. Sangsawang et al. (2017) also observed a 4-fold increased DDN assimilation into the tissue of bleached $P$. lutea corals, whereas assimilation by endoliths was similar in bleached and non-bleached corals. However, they identified that part of the tissue-assimilated DDN was fixed and translocated from the endolithic compartment, and similarly, translocation of DDN between the individual compartments may have occurred in the present study.

Overall, a mutual exchange of both fixed $\mathrm{C}$ and $\mathrm{N}$ between diazotrophs, photosynthesizing endolithic algae and the coral host may allow $O$. patagonica to nutritionally survive and successfully recover from annual bleaching during the oligotrophic summer period (RodolfoMetalpa et al., 2014). Here, we induced the bleaching phenotype of $O$. patagonica via heat stress, similar to what this coral experiences during exceptionally high seawater temperature in the North or South Mediterranean Sea. In addition, O. patagonica from the Northern Mediterranean Sea can also be affected by severe bleaching, polyp dissociation and tissue loss due to cold winter temperatures $\left(<12^{\circ} \mathrm{C}\right)$, but regularly recovers the lost tissue during spring and summer (Serrano et al., 2017). The tissue regeneration capacity $\left(10.3 \mathrm{~mm}^{2} \mathrm{~d}^{-1}\right)$ is one of the highest reported for a coral species at high latitudes and this biological characteristic allows $O$. patagonica to withstand and survive unfavourable cold temperature conditions (Henry and Hart, 2005; Serrano et al., 2017). Therefore, future experiments could investigate whether DDN can be an important nutrient source during/after cold temperature stress fostering the regenerative capacity of $O$. patagonica. This will help to better understand the 
nutritional performance of corals at high latitudes and their resilience to cold and warm temperature stress.

\section{Conclusion}

Overall, we show that the temperate coral species $O$. patagonica is tightly associated with a diverse community of active diazotrophs. The animal tissue and skeleton are hotspots for DDN assimilation and the relative high abundance of autotrophic Cyanobacteria and Chlorobia suggest that they may be key members of the diazotrophic community. This corroborates previous predictive metagenomic analysis showing that metabolic functions linked to the $\mathrm{N}$ cycle are highly abundant in the core microbiome of $O$. patagonica (RubioPortillo et al., 2016). We suggest that (i) autotrophic diazotrophs may provide a source of both $\mathrm{C}$ and $\mathrm{N}$ to the coral symbiosis, and that (ii) DDN possibly supports the rapid proliferation of an endolithic algal community in bleached corals. Taken together, diazotrophs may constitute an additional biological characteristic that can benefit the high regenerative capacity of this coral species to survive and recover from annual summer bleaching events. To better understand the role of $\mathrm{N}_{2}$ fixation for the nutritional performance of corals in the context of global warming, more holistic studies will be required that aim at investigating the activity, diversity and abundance of diazotrophs in bleached and recovered coral colonies, the temperature sensitivity of the different coral symbionts (i.e. diazotrophs, Symbiodinium and endolithic algae), as well as tracing the transfer of $\mathrm{C}$ and $\mathrm{N}$ between the different partners of the coral holobiont.

\section{Experimental Procedures}




\section{Sample collection and experimental design}

A total of 26 O. patagonica colonies (surface area ranged from 17 to $30 \mathrm{~cm}^{2}$ ), that appeared healthy from visual inspection without any signs of bleaching or tissue lesion, were collected at Albissola, in the Gulf of Genoa, Mediterranean Sea at $3 \mathrm{~m}$ depth. Six of the coral colonies were used directly for the determination of the overall bacterial and diazotrophic community composition (nifH and 16S rRNA amplicon sequencing), as described below, while the remaining 20 colonies were transported back to the aquarium facilities of the Centre Scientifique de Monaco. These 20 colonies were distributed across four 20L aquaria (two aquaria per treatment with five colonies per aquaria), which were continuously supplied with natural seawater pumped directly from the Mediterranean Sea at a flow rate equal to $20 \mathrm{~L} \mathrm{~h}^{-1}$. This ensured constant in situ water temperature $\left(16^{\circ} \mathrm{C} \pm 0.5^{\circ} \mathrm{C}\right), \mathrm{pH}$, dissolved oxygen concentrations and oligotrophic nutrient conditions $(\sim 0.5 \mu \mathrm{M}$ nitrate and $\sim 0.1 \mu \mathrm{M}$ phosphate). Irradiance was adjusted to a non-stressful level of $150 \mu \mathrm{mol}$ photons $\mathrm{m}^{-2} \mathrm{~s}^{-1}(12 \mathrm{~h}$ light:12h dark photoperiod) via 400 Watt HQI metal halide lamps, as previously used in studies on Mediterranean anthozoans (Rodolfo-Metalpa et al., 2008; Ezzat et al., 2013; Linares et al., 2013). Coral colonies were fed twice a week for $1 \mathrm{~h}$ with Artemia salina nauplii for the total duration of the experiment. After allowing the remaining 20 coral colonies to acclimate in the aquaria for 8 weeks, the temperature in two tanks was gradually increased $\left(1^{\circ} \mathrm{C}\right.$ every 2 days $)$ up to $28^{\circ} \mathrm{C} \pm 0.5^{\circ} \mathrm{C}$ using electronic controlled heaters, while the temperature in the other two tanks was maintained at $16^{\circ} \mathrm{C} \pm 0.5^{\circ} \mathrm{C}$. The final temperature $\left(16^{\circ} \mathrm{C}\right.$ or $28^{\circ} \mathrm{C}$, respectively $)$ in each tank was kept constant for a total period of three weeks before the skeletal surface area of all colonies was determined using the Advanced Geometry technique (Naumann et al., 2009) and colonies were subsequently used for the incubation experiments as described below. Six colonies per treatment (three from each duplicate tank) were first used to determine key physiological parameters, before the ${ }^{15} \mathrm{~N}_{2}$ tracer experiments were conducted 
on the same specimens. The remaining four colonies per treatment (two from each duplicate tank) served as controls for the ${ }^{15} \mathrm{~N}_{2}$ incubation experiments to determine the natural ${ }^{15} \mathrm{~N}$ signature of the corals. All of the incubation experiments were conducted under conditions equal to the experimental tanks, using a water bath to ensure the correct treatment temperature in the incubation chambers.

\section{Overall bacterial and diazotrophic community analysis}

\section{DNA extraction and amplicon tag sequencing}

The freshly collected $O$. patagonica colonies $(\mathrm{n}=6)$ were rinsed with $0.22 \mu \mathrm{m}$ filtered seawater for approximately $10 \mathrm{~min}$ to retrieve the mucus. The mucus-containing seawater $(n=6)$ and additional seawater samples (samples without mucus; $n=3$ ) were filtered onto $0.2-\mu \mathrm{m}$ Nuclepore Whatman filters, respectively, to compare the mucus-associated community with those present in the seawater. Thereafter, all $0.2-\mu \mathrm{m}$ filter retentates and the rinsed coral colonies were preserved in RNAlater (ThermoFisherScientific, USA) at $4^{\circ} \mathrm{C}$.

From all coral colonies, the tissue was removed from approximately $2-3 \mathrm{~cm}^{2}$ of skeleton surface area using an air-brush, homogenized and centrifuged to pellet the total cellular material of the tissue slurry (animal tissue + Symbiodinium). Genomic DNA was extracted from the tissue slurry and the Nuclepore filters (coral mucus and seawater controls) using the Genomic DNA Buffer Set and Genomic-tip 20/G columns (QIAGEN, Germany) following the manufacturer's sample preparation and lysis protocol for tissues. Extracted DNA was quantified using a Nanodrop ND-1000 spectrofluorometer (Nanodrop Technologies, USA) and samples were sent to the Research and Testing Laboratory (MR DNA, USA) for gene-specific (nifH and the 16S rRNA) amplicon sequencing. 
Libraries were constructed using (i) the 27Fmod (AGRGTTTGATCMTGGCTCAG) (Eden et al., 1991) and the 519Rmod (GTNTTACNGCGGCKGCTG) (Frank et al., 2013) primer pair targeting the variable region V1-V3 of the 16S rRNA gene to assess the overall bacterial community structure, and (ii) primers (mnifHF 'TGYGAYCCNAARGCNGA', mnifHR 'ADNGCCATCATYTCNCC') (Zehr and McReynolds, 1989) targeting the variable region (360bp) of the nifH gene to specifically identify the diazotrophic community. Samplespecific barcodes were present on the forward primers. Amplicons were generated in a 28 cycle PCR (initialization: $94^{\circ} \mathrm{C}$ for 3 minutes; amplification of 28 cycles: $94^{\circ} \mathrm{C}$ for 30 seconds, $53^{\circ} \mathrm{C}$ for 40 seconds and $72^{\circ} \mathrm{C}$ for 1 minute; final elongation: $72^{\circ} \mathrm{C}$ for 5 minutes) using the HotStarTaq Plus Master Mix Kit (Qiagen, USA). Samples were pooled in equal proportions, taking into account the molecular weight and DNA concentrations of the amplicons. The pooled samples were purified using calibrated Agencourt AMPure XP beads (Beckman Coulter) and sequencing libraries were subsequently prepared using the TruSeq Nano DNA LT Library Prep Kit (Illumina). Amplicon libraries were paired-end (2x300bp) sequenced on the Illumina MiSeq platform.

$16 S$ rRNA and nifH sequence analyses

The 16S rRNA gene amplicon data was analyzed using the QIIME pipeline (Caporaso et al., 2010). The raw quality (.qual) and reads (.fasta) files provided by the Research and Testing Laboratory (MR DNA, USA) contained 1,685,436 reads with an average length of 507bp. Reads were quality trimmed using the split_libraries.py script to remove primers, barcodes and low quality (Phred $<25)$ sequences, and to assign each read to its respective sample, and chimeric sequences were subsequently removed using UCHIME (Edgar et al., 2011), generating a filtered fasta file containing 1,526,484 reads with an average length of 462bp. A total of 306,228 OTUs were defined at 97\% similarity level and taxonomy was assigned based on the SILVA database (release v123) (Quast et al., 2013) using the UCLUST 
algorithm (Edgar, 2010). Singletons, unassigned OTUs, and OTUs classified as chloroplast or mitochondria were excluded from the dataset. The final OTU table contained 965,454 reads belonging to 29,750 OTUs, with an average of 64,363 reads per sample (min 27,737; max 111,548). The OTU table was rarefied to 27,737 reads per sample, before alpha diversity metrics and both unweighted and weighted UniFrac distance matrices were calculated from the OTU table (Supplementary File S1) using the QIIME pipeline. Bacterial community composition was determined for coral tissue, mucus and seawater and graphical presentations of the microbiome data were generated using the phyloseq package in $\mathrm{R}$ (McMurdie and Holmes, 2013).

The nifH gene amplicon dataset was processed using the TaxADiva (TAXonomy Assignment and DIVersity Assessment) pipeline (Gaby et al., 2018), followed by Minimum Entropy Decomposition (MED; Eren et al., 2015). In short, raw forward and reverse reads (each 746,867 reads with average length of 295bp; min 20,051 reads; max 126,402 reads) were merged with Paired-End reAd mergeR (PEAR; REF Zhang et al., 2014) and merged reads $<300 \mathrm{bp}$ and $>450 \mathrm{bp}$ were removed. Primer sequences were removed using Prinseq (both sides 17bp) (http://prinseq.sourceforge.net/) and chimeric sequences were removed with VSEARCH (Rognes et al., 2016). MED analysis was used to cluster the remaining 527,949 merged reads (average length of 333bp) into unique oligotypes and identify matches to the nifH sequence database (provided with TaxADiva). Of the 244 oligotypes identified, 85 showed a BLAST hit with the nifH sequence database and were selected for further analysis. The remaining oligotypes were queried against the non-redundant database using BLASTx, and it was confirmed that these were indeed not nifH-encoding sequences. The selected 85 nifH oligotypes (representing 170,755 reads; reads per sample: minimum 1,016 and maximum 61,791 reads) were clustered at the 95\% similarity level using USEARCH (Edgar, 2010), resulting in 24 nifH OTUs, and an OTU table (Supplementary File S2) was generated. 
Representative sequences of each nifH OTU were loaded into MEGA 6 (Tamura et al., 2013) and translated to peptide sequences for further taxonomic analysis. Peptide sequences were queried against the non-redundant protein sequence database using BLASTp (with uncultured and environmental sample sequences excluded), curated RefSeq matches along with the nifH sequences previously found in corals (Olson et al., 2009; Lema et al., 2012; Lesser et al., 2018) and several nifH paralogs (belonging to Cluster II and IV) were aligned with the 24 novel nifH OTUs using the CLUSTALW algorithm. A 133 amino acid (including gaps) long alignment matrix was selected and a Maximum-Likelihood phylogenetic tree reconstruction was performed based on the Whelan and Goldman (WAG) model using 1000 replicate bootstraps to ascertain node support. Final taxonomy of the newly identified nifH sequences was inferred based on their placement within the phylogenetic tree. The nifH OTU table was rarefied to 1016 reads per sample prior to alpha and beta diversity analysis (Supplementary File S2). Sequences of the 24 nifH oligotypes were deposited with the NCBI GenBank under sequence accession numbers MH448080-MH448103. All raw sequence data for $16 \mathrm{~S}$ and nifH are accessible at the NCBI Sequence Read Archive under accession number SRP118527.

\section{Quantification of key physiological parameters}

After three weeks temperature treatment period, heterotrophic feeding experiments were conducted by incubating each coral colony $(n=6)$ individually in $6 \mathrm{~L}$ thermally regulated flow chambers completely filled with GF/F filtered seawater. Additional chambers (without corals, $n=4$ ) served as seawater controls. Water circulation in each chamber was provided by a motor-driven propeller with a defined rotational speed $\left(1.7 \mathrm{~cm} \mathrm{~s}^{-1}\right)$ as used in previous feeding experiments (Tremblay et al., 2011). After the coral polyps were expanded, Artemia salina nauplii were added to each chamber for a final concentration of 4000 nauplii $1^{-1}$. Using a glass 
pipette triplicate, $10 \mathrm{ml}$ seawater samples were taken from each chamber at $20 \mathrm{~min}$ intervals over a total of $2 \mathrm{~h}$. The number of nauplii in the $10 \mathrm{ml}$ was determined visually before the water was put back to the chamber to avoid any artificial decrease in the nauplii concentration during the incubation period. Finally, grazing rates were calculated as the decrease in nauplii concentration over time and the respective $\mathrm{N}$ input from grazing was calculated considering 2h feeding per week, the $\mathrm{N}$ content $\left(0.25 \pm 0.01 \mu \mathrm{g} \mathrm{N}\right.$ nauplii $\left.{ }^{-1}\right)$ of the prey (Tremblay et al., 2011), and a $\mathrm{N}$ assimilation efficiency of 50\% under high food supply (Anthony, 2000). This was used in order to compare the $\mathrm{N}$ input from Artemia salina nauplii with that from DDN assimilation.

Oxygen flux measurements were used to assess net photosynthesis $\left(P_{\mathrm{n}}\right)$ and dark $R$ rates $(n=6)$. Each coral colony was incubated under constant stirring in a thermally regulated beaker completely filled with GF/F filtered seawater. Oxygen fluxes were monitored over 60min (in 1min intervals) in the dark ( $R$ rates) and at $150 \mu \mathrm{mol}$ quanta $\mathrm{m}^{-2} \mathrm{~s}^{-1}\left(P_{\mathrm{n}}\right.$ rates), respectively, using Unisense optodes connected to a computer with OXY-4 software (Chanel fiber-optic oxygen meter, PreSens, Germany). Optodes were calibrated against $\mathrm{N}_{2}$-saturated and air-saturated seawater for $0 \%$ and $100 \%$ oxygen saturation, respectively. $P_{\mathrm{n}}$ and $R$ rates were calculated by regressing oxygen data against time and normalizing the rates to both, incubation volume and skeletal surface area $\left(\mathrm{cm}^{2}\right)$ of the coral colony. Finally, $P_{\mathrm{g}}$ was calculated according to $P_{\mathrm{g}}=P_{\mathrm{n}}-R$. The maximum quantum yield of PSII $(F v / F m)$ of Symbiodinium was measured on each coral fragment (10min dark-adapted) using a pulse amplitude modulation (PAM) fluorometer (DIVING-PAM, Walz, Germany).

\title{
Quantification of $\mathbf{N}_{2}$ fixation rates
}

\author{
${ }^{15} \mathrm{~N}_{2}$ incubation
}


The ${ }^{15} \mathrm{~N}_{2}$-enriched seawater addition method (Mohr et al., 2010) was used to quantify DDN assimilation into the different compartments of O. patagonica (i.e. tissue, Symbiodinium, coral mucus and coral skeleton). ${ }^{15} \mathrm{~N}_{2}$-enriched seawater was produced the day before incubation by injecting $3 \mathrm{ml}^{15} \mathrm{~N}_{2}$ gas (98\% Eurisotop) per $100 \mathrm{ml}$ of degassed $0.2 \mu \mathrm{m}$ filtered seawater followed by vigorous shaking overnight. Corals ( $n=6$ per treatment) were placed individually into $500 \mathrm{ml}$ glass beakers completely filled with $0.2 \mu \mathrm{m}$ filtered seawater and amended with $10 \%$ vol:vol ${ }^{15} \mathrm{~N}_{2}$-enriched seawater. Subsamples of the incubation water were withdrawn and analysed on a Membrane Inlet Mass Spectrometer (MIMS) to determine the ${ }^{15} \mathrm{~N}$ enrichment of the $\mathrm{N}_{2}$ pool in the incubation bottles $\left(10.87 \pm 0.23\right.$ atom $\left.\%{ }^{15} \mathrm{~N}\right)$. All beakers were closed gastight without headspace and incubated under constant stirring (350rpm) and maintenance light condition (12h light: $12 \mathrm{~h}$ dark cycle) in a temperature controlled water bath over $24 \mathrm{~h}$. Additional beakers with corals but without ${ }^{15} \mathrm{~N}_{2}$ addition were incubated in parallel to determine the coral's background ${ }^{15} \mathrm{~N}$ signatures ( $\mathrm{n}=4$ per treatment). At the end of the incubation, coral colonies were collected from the chambers, rinsed with filtered seawater to remove their mucus and stored frozen until ${ }^{15} \mathrm{~N}$ analysis of the different compartments. The remaining incubation water containing mucus particles released by the coral during the incubation was filtered onto pre-combusted $\left(400^{\circ} \mathrm{C}, 4-5 \mathrm{~h}\right) \mathrm{GF} / \mathrm{F}$ filters which were dried $\left(60^{\circ} \mathrm{C}, 24 \mathrm{~h}\right)$ to analyse the ${ }^{15} \mathrm{~N}$ content of the mucus particles.

\section{Sample analysis}

The coral tissue was removed from the skeleton using an air-brush and the homogenized tissue slurry was separated in into the animal and algal fractions via centrifugation $(2000 \mathrm{xg}$ for $10 \mathrm{~min}$ at $4^{\circ} \mathrm{C}$ ) (Grover et al., 2002). The supernatant was centrifuged three times to pellet residual algal and the algal pellet was resuspended and washed three times with filtered seawater to avoid tissue contamination. The separated tissue and Symbiodinium samples were subsequently freeze-dried. The remaining skeleton was dried in an oven $\left(60^{\circ} \mathrm{C}, 48 \mathrm{~h}\right)$ and 
ground to powder using a CryoMill (Retsch, Germany). Finally, the organic N content together with its ${ }^{15} \mathrm{~N}$ enrichment was quantified in all samples using a mass spectrometer (Delta Plus, Thermofisher Scientific, Germany) coupled via a type III interface to a $\mathrm{C} / \mathrm{N}$ analyzer (Flash EA, Thermofisher Scientific, Germany). The standard deviation obtained from repeated measurements of standards was better than $0.5 \mu \mathrm{g}$ for particulate nitrogen $(\mathrm{PN})$ in the range used $(5-50 \mu \mathrm{g} \mathrm{N})$, and was $<0.0001$ atom $\%$ for ${ }^{15} \mathrm{~N}$ enrichment. The ${ }^{15} \mathrm{~N}$ excess enrichment for each sample was calculated with the formula:

$$
\text { Atom } \%{ }^{15} N_{\text {excess }}=\left[\text { atom } \%{ }^{15} N_{\text {sample }}-\text { atom } \%{ }^{15} N_{\text {control }}\right],
$$

where atom $\%{ }^{15} \mathrm{~N}_{\text {sample }}$ is the ${ }^{15} \mathrm{~N}$ enrichment of samples after exposure to ${ }^{15} \mathrm{~N}_{2}$-enriched seawater and atom $\%{ }^{15} \mathrm{~N}_{\text {control }}$ is the natural ${ }^{15} \mathrm{~N}$ enrichment of control corals. The atom $\%$ ${ }^{15} \mathrm{~N}_{\text {excess }}$ was considered significant when it was at least three times higher than the standard deviation obtained on atom $\%{ }^{15} \mathrm{~N}_{\text {control. }}$. Finally, DDN assimilation into the different coral compartments was calculated by the following equation (Montoya et al., 1996):

$$
\begin{gathered}
\text { DDN assimilation }=\left[\text { atom } \%{ }^{15} N_{\text {excess }} /\left(t \text { x atom } \%{ }^{15} N_{\text {incubation water }}\right)\right] \times\left[\mu g P N_{\text {sample }} \mathrm{cm}^{-2} \text { or } \mu g^{-}\right. \\
\left.{ }^{1} \text { dry weight }\right]
\end{gathered}
$$

where $t$ is the incubation time, atom $\%{ }^{15} N_{\text {incubation water }}$ is the ${ }^{15} \mathrm{~N}$ enrichment of the $\mathrm{N}_{2}$ pool in the ${ }^{15} \mathrm{~N}$ enriched incubation water (atom $\%{ }^{15} N_{\text {enriched water }}-$ atom $\%{ }^{15} N_{\text {non-enriched water }}$ ) and $P N_{\text {sample }} / \mathrm{cm}^{2}$ and total dry weight is the PN content of the sample at the end of the incubation normalized per $\mathrm{cm}^{2}$ coral skeletal surface area or alternatively normalized per dry weight of the coral colony. DDN assimilation rates of each compartment were also normalized to the specific dry weight of the corresponding compartment in order to compare the amount of DDN assimilated per compartment biomass between healthy and bleached corals. 
The dry weight of the separated and freeze-dried algal fraction of each colony was also used to express the Symbiodinium content as algal dry weight normalized per skeletal surface area.

\section{Statistical analysis}

Differences in alpha and beta diversity of the overall and diazotrophic bacterial community associated with the coral tissue, mucus and seawater were analyzed with one-factor (coral compartment) permutational multivariate analyses of variance (PERMANOVA) using Primer-E version 6 software (Clarke and Gorley, 2006) with the PERMANOVA+ add on (Anderson, 2001). Beta diversity analyses were based on the weighted and unweighted UniFrac distance metric (16S rRNA - overall bacterial community) or a Bray-Curtis similarity matrix with square-root transformed data (nifH - diazotrophic community) with Type III partial sums of squares and unrestricted permutation of the raw data (9999 permutations). Alpha diversity analyses were based on a Euclidean distance matrix with square-root transformed data with Type III partial sums of squares and unrestricted permutation of the raw data (9999 permutations). Differences in DDN assimilation rates were analyzed with a two-factor PERMANOVA with coral compartment (coral tissue, Symbiodinium, skeleton and coral mucus) and coral condition (healthy vs bleached) as fixed effects. Analysis was based on Euclidean distance and type III partial sums of squares were used with permutation of residuals under a reduced model (9999 permutations). The significance for both the main test and the pair-wise comparisons was based on Monte Carlo (MC) tests. Total DDN assimilation (including all four compartments), compartment-specific DDN assimilation normalized to the dry weight of the respective compartment and all key physiological parameters were compared between healthy and bleached corals using individual Student's t-tests. 


\section{Acknowledgements}

We want to thank Prof. D. Allemand, Director of the Centre Scientifique de Monaco, for scientific support, Cecile Rottier, Naïs Favre and Antoine Labbe for help with sample analysis, Olivier Grosso, engineer at the Institut Méditerranéen d'Océanologie (Luminy) for MIMS measurements, and Lucile Courtial for fruitful discussions.

\section{Competing interests}

The authors declare no conflict of interest.

\section{References}

Ainsworth, T., Fine, M., Roff, G., and Hoegh-Guldberg, O. (2008) Bacteria are not the primary cause of bleaching in the Mediterranean coral Oculina patagonica. ISME J. 288: $67-73$

Anderson, M.J. (2001) A new method for non-parametric multivariate analysis of variance. Austral Ecol. 26: 32-46.

Anthony, K.R.N. (2000) Enhanced particle-feeding capacity of corals on turbid reefs (Great Barrier Reef, Australia). Coral Reefs 19: 59-67.

Bednarz, V.N., Grover, R., Maguer, J.-F., Fine, M., and Ferrier-Pagès, C. (2017) The Assimilation of diazotroph-derived nitrogen by scleractinian corals depends on their metabolic status. MBio 8: doi: 10.1128/mBio.02058-16.

Benavides, M., Bednarz, V.N., and Ferrier-Pagès, C. (2017) Diazotrophs: Overlooked key 
players within the coral symbiosis and tropical reef ecosystems? Front. Mar. Sci. 4: doi: 10.3389/fmars.2017.00010.

Benavides, M., Houlbrèque, F., Camps, M., Lorrain, A., Grosso, O., and Bonnet, S. (2016) Diazotrophs: a non-negligible source of nitrogen for the tropical coral Stylophora pistillata. J. Exp. Biol. 219: 2608-2612.

Béraud, E., Gevaert, F., Rottier, C., and Ferrier-Pagès, C. (2013) The response of the scleractinian coral Turbinaria reniformis to thermal stress depends on the nitrogen status of the coral holobiont. J. Exp. Biol. 216: 2665-2674.

Cai, L., Zhou, G., Tian, R.-M., Tong, H., Zhang, W., Sun, J., et al. (2017) Metagenomic analysis reveals a green sulfur bacterium as a potential coral symbiont. Sci. Rep. 7: 9320.

Capone, D.G., Zehr, J.P., Paerl, H.W., Bergman, B., and Carpenter, E.J. (1997)

Trichodesmium, a globally significant marine cyanobacterium. Science. 276: 1221-1229.

Caporaso, G.J., Kuczynski, J., Stombaugh, J., Bittinger, K., Bushman, F.D., Costello, E.K., et al. (2010) QIIME allows analysis of high-throughput community sequencing data. Nat. Methods 7: 335-336.

Cardini, U., Bednarz, V.N., Foster, R.A., and Wild, C. (2014) Benthic $\mathrm{N}_{2}$ fixation in coral reefs and the potential effects of human-induced environmental change. Ecol. Evol. 4: $1706-1727$.

Cardini, U., Bednarz, V.N., van Hoytema, N., Rovere, A., Naumann, M.S., Al-Rshaidat, M.M.D., and Wild, C. (2016) Budget of primary production and dinitrogen fixation in a highly seasonal Red Sea coral reef. Ecosystems 19: 771-785.

Cardini, U., Bednarz, V.N., Naumann, M.S., van Hoytema, N., Rix, L., Foster, R.A., et al. (2015) Functional significance of dinitrogen fixation in sustaining coral productivity 
under oligotrophic conditions. Proc. R. Soc. London B Biol. Sci. 282: 20152257.

Cardini, U., van Hoytema, N., Bednarz, V.N., Rix, L., Foster, R.A., Al-Rshaidat, M.M.D., and Wild, C. (2016) Microbial dinitrogen fixation in coral holobionts exposed to thermal stress and bleaching. Environ. Microbiol. 18: 2620-2633.

Ceh, J., Kilburn, M.R., Cliff, J.B., Raina, J.-B., van Keulen, M., and Bourne, D.G. (2013) Nutrient cycling in early coral life stages: Pocillopora damicornis larvae provide their algal symbiont (Symbiodinium) with nitrogen acquired from bacterial associates. Ecol. Evol. 3: 2393-2400.

Clarke, K.R. and Gorley, R.N. (2006) Primer version 6: user manual/tutorial Primer-E. Plymouth, England.

Coma, R., Gili, J., Zabala, M., and Riera, T. (1994) Feeding and prey capture cycles in the aposymbiontic gorgonian Paramuricea clavata. Mar. Ecol. Prog. Ser. 115: 257-270.

Coma, R. and Ribes, M. (2003) Seasonal energetic constraints in Mediterranean benthic suspension feeders: effects at different levels of ecological organization. Oikos 101: 205215.

Coma, R., Ribes, M., Gili, J., and Zabala, M. (2000) Seasonality in coastal benthic ecosystems. Trends Ecol. Evol. 15: 448-453.

Cunning, R., Muller, E.B., Gates, R.D., and Nisbet, R.M. (2017) A dynamic bioenergetic model for coral-Symbiodinium symbioses and coral bleaching as an alternate stable state. J. Theor. Biol. 431: 49-62.

D’Ortenzio, F. and Ribera d'Alcalà, M. (2009) On the trophic regimes of the Mediterranean Sea: a satellite analysis. Biogeosciences 6: 139-148. 
Dron, A., Rabouille, S., Claquin, P., Le Roy, B., Talec, A., and Sciandra, A. (2012) Lightdark (12:12) cycle of carbon and nitrogen metabolism in Crocosphaera watsonii WH8501: relation to the cell cycle. Environ. Microbiol. 14: 967-981.

Dron, A., Rabouille, S., Claquin, P., Talec, A., Raimbault, V., and Sciandra, A. (2013) Photoperiod length paces the temporal orchestration of cell cycle and carbon-nitrogen metabolism in Crocosphaera watsonii. Environ. Microbiol. 15: 3292-3304.

Dubinsky, Z. and Jokiel, P. (1994) Ratio of energy and nutrient fluxes regulates symbiosis between zooxanthellae and corals. Pacific Sci. 48: 313-324.

Eden, P.A., Schmidt, T.M., Blakemore, R.P., and Pace, N.R. (1991) Phylogenetic analysis of Aquaspirillum magnetotacticum using polymerase chain reaction-amplified $16 \mathrm{~S}$ rRNAspecific DNA. Int. J. Syst. Bacteriol. 41: 324-325.

Edgar, R.C. (2010) Search and clustering orders of magnitude faster than BLAST. Bioinformatics 26: 2460-2461.

Edgar, R.C., Haas, B.J., Clemente, J.C., Quince, C., and Knight, R. (2011) UCHIME improves sensitivity and speed of chimera detection. Bioinformatics 27: 2194-2200.

Eren, A.M., Morrison, H.G., Lescault, P.J., Reveillaud, J., Vineis, J.H., and Sogin, M.L. (2015) Minimum entropy decomposition: Unsupervised oligotyping for sensitive partitioning of high-throughput marker gene sequences. ISME J. 9: 968-979.

Erwin, P.M. and Thacker, R.W. (2008) Phototrophic nutrition and symbiont diversity of two Caribbean sponge-cyanobacteria symbioses. Mar. Ecol. Prog. Ser. 362: 139-147.

Ezzat, L., Merle, P., Furla, P., Buttler, A., and Ferrier-Pagès, C. (2013) The response of the Mediterranean gorgonian Eunicella singularis to thermal stress is independent of its nutritional regime. PLoS One 8: e64370. 
Ferrer, L.M. and Szmant, A.M. (1988) Nutrient regeneration by the endolithic community in coral skeletons. In, Proceedings of the 6th international Coral Reef Symposium., pp. 1-4.

Fine, M. and Loya, Y. (2002) Endolithic algae: an alternative source of photoassimilates during coral bleaching. Proc. R. Soc. 269: 1205-1210.

Fine, M., Oren, U., and Loya, Y. (2002) Bleaching effect on regeneration and resource translocation in the coral Oculina patagonica. Mar. Ecol. Prog. Ser. 234: 119-125.

Fiore, C., Jarett, J., Olson, N., and Lesser, M. (2010) Nitrogen fixation and nitrogen transformations in marine symbioses. Trends Microbiol. 18: 455-463.

Foster, R. a, Kuypers, M.M.M., Vagner, T., Paerl, R.W., Musat, N., and Zehr, J.P. (2011) Nitrogen fixation and transfer in open ocean diatom-cyanobacterial symbioses. ISME J. 5: 1484-1493.

Frank, K.L., Rogers, D.R., Olins, H.C., Vidoudez, C., and Girguis, P.R. (2013) Characterizing the distribution and rates of microbial sulfate reduction at Middle Valley hydrothermal vents. ISME J. 7: 1391-1401.

Gaby, J.C., Rishishwar, L., Valderrama-Aguirre, L.C., Green, S.J., Valderrama-Aguirre, A., Jordan, I.K., and Kostka, J.E. (2018) Diazotroph community characterization via a highthroughput nifH amplicon sequencing and analysis pipeline. Appl. Environ. Microbiol. 84: e01512-17.

Glibert, P.M. and Bronk, D.A. (1994) Release of dissolved organic nitrogen by marine diazotrophic cyanobacteria, Trichodesmium spp. Appl. Environ. Microbiol. 60: 39964000.

Grover, R., Maguer, J.F., Reynaud-Vaganay, S., and Ferrier-Pagès, C. (2002) Uptake of ammonium by the scleractinian coral Stylophora pistillata: effect of feeding, light, and 
ammonium concentrations. Limnol. Oceanogr. 47: 782-790.

Henry, L.-A. and Hart, M. (2005) Regeneration from injury and resource allocation in sponges and corals - a review. Int. Rev. Hydrobiol. 90: 125-158.

Koren, O. and Rosenberg, E. (2006) Bacteria associated with mucus and tissues of the coral Oculina patagonica in summer and winter. Appl. Environ. Microbiol. 72: 5254-5259.

Kushmaro, A., Loya, Y., Fine, M., and Rosenberg, E. (1996) Bacterial infection and coral bleaching. Nature 380: 396.

Kushmaro, A., Rosenberg, E., Fine, M., and Haim, Y. (1998) Effect of temperature on bleaching of the coral Oculina patagonica by Vibrio AK-1. Mar. Ecol. Prog. 171: 131137.

Lema, K., Bourne, D., and Willis, B. (2014) Onset and establishment of diazotrophs and other bacterial associates in the early life history stages of the coral Acropora millepora. Mol. Ecol. 23: 4682-4695.

Lema, K., Willis, B., and Bourne, D. (2014) Amplicon pyrosequencing reveals spatial and temporal consistency in diazotroph assemblages of the Acropora millepora microbiome. Environ. Microbiol. 16: 3345-3359.

Lema, K., Willis, B., and Bourne, D. (2012) Corals form characteristic associations with symbiotic nitrogen-fixing bacteria. Appl. Environ. Microbiol. 78: 3136-3144.

Lesser, M., Morrow, K., Pankey, S., and Noonan, S. (2018) Diazotroph diversity and nitrogen fixation in the coral Stylophora pistillata from the Great Barrier Reef. ISME J. 12: 813824.

Linares, C., Cebrian, E., Kipson, S., and Garrabou, J. (2013) Does thermal history influence 
the tolerance of temperate gorgonians to future warming? Mar. Environ. Res. 89: 45-52.

McMurdie, P.J. and Holmes, S. (2013) phyloseq: an R package for reproducible interactive analysis and graphics of microbiome census data. PLoS One 8: e61217.

Middelburg, J.J., Mueller, C.E., Veuger, B., Larsson, A.I., Form, A., and van Oevelen, D. (2015) Discovery of symbiotic nitrogen fixation and chemoautotrophy in cold-water corals. Sci. Rep. 5: 17962.

Mills, E., Shechtman, K., Loya, Y., and Rosenberg, E. (2013) Bacteria appear to play important roles in both causing and preventing the bleaching of the coral Oculina patagonica. Mar. Ecol. Prog. Ser. 489: 155-162.

Le Moal, M. and Biegala, I.C. (2009) Diazotrophic unicellular cyanobacteria in the northwestern Mediterranean Sea: A seasonal cycle. Limnol. Oceanogr. 54: 845-855.

Mohamed, N.M., Colman, A.S., Tal, Y., and Hill, R.T. (2008) Diversity and expression of nitrogen fixation genes in bacterial symbionts of marine sponges. Environ. Microbiol. 10: $2910-2921$.

Mohr, W., Grosskopf, T., Wallace, D.W.R., and LaRoche, J. (2010) Methodological underestimation of oceanic nitrogen fixation rates. PLoS One 5: e12583.

Montoya, J., Holl, C.M., Zehr, J.P., Hansen, A., Villareal, T.A., and Capone, D.G. (2004) High rates of $\mathrm{N}_{2}$ fixation by unicellular diazotrophs in the oligotrophic Pacific Ocean. Nature 430: 1027-1032.

Montoya, J., Voss, M., Kähler, P., and Capone, D.G. (1996) A simple, high-precision, highsensitivity tracer assay for $\mathrm{N}_{2}$ fixation. Appl. Environ. Microbiol. 62: 986-993.

Mulholland, M.R. and Bernhardt, P.W. (2005) The effect of growth rate, phosphorus 
concentration, and temperature on $\mathrm{N}_{2}$ fixation, carbon fixation, and nitrogen release in continuous cultures of Trichodesmium IMS101. Limnol. Oceanogr. 50: 839-849.

Naumann, M.S., Niggl, W., Laforsch, C., Glaser, C., and Wild, C. (2009) Coral surface area quantification-evaluation of established techniques by comparison with computer tomography. Coral Reefs 28: 109-117.

Olson, N. and Lesser, M. (2013) Diazotrophic diversity in the Caribbean coral, Montastraea cavernosa. Arch. Microbiol. 195: 853-859.

Olson, N.D., Ainsworth, T.D., Gates, R.D., and Takabayashi, M. (2009) Diazotrophic bacteria associated with Hawaiian Montipora corals: Diversity and abundance in correlation with symbiotic dinoflagellates. J. Exp. Mar. Bio. Ecol. 371: 140-146.

Pedrós-Alió, C., Calderón-Paz, J.-I., Guixa-Boixereu, N., Estrada, M., and Gasol, J.M. (1999) Bacterioplankton and phytoplankton biomass and production during summer stratification in the northwestern Mediterranean Sea. Deep Sea Res. Part I Oceanogr. Res. Pap. 46: 985-1019.

Pernice, M., Meibom, A., Van Den Heuvel, A., Kopp, C., Domart-Coulon, I., HoeghGuldberg, O., and Dove, S. (2012) A single-cell view of ammonium assimilation in coral-dinoflagellate symbiosis. ISME J. 6: 1314-1324.

Plass-Johnson, J., Cardini, U., van Hoytema, N., Bayraktarov, E., Burghardt, I., Naumann, M., and Wild, C. (2015) Coral Bleaching. In, Environmental Indicators. Springer Netherlands, Dordrecht, pp. 117-146.

Pogoreutz, C., Rädecker, N., Cárdenas, A., Gärdes, A., Voolstra, C.R., and Wild, C. (2017) Sugar enrichment provides evidence for a role of nitrogen fixation in coral bleaching. Glob. Chang. Biol. 23: 3838-3848. 
Quast, C., Pruesse, E., Yilmaz, P., Gerken, J., Schweer, T., Yarza, P., et al. (2013) The SILVA ribosomal RNA gene database project: improved data processing and web-based tools. Nucleic Acids Res. 41: D590-D596.

Rabouille, S., Semedo Cabral, G., and Pedrotti, M. (2017) Towards a carbon budget of the diazotrophic cyanobacterium Crocosphaera: effect of irradiance. Mar. Ecol. Prog. Ser. 570: $29-40$.

Ridame, C., Le Moal, M., Guieu, C., Ternon, E., Biegala, I.C., L’Helguen, S., and Pujo-Pay, M. (2011) Nutrient control of $\mathrm{N}_{2}$ fixation in the oligotrophic Mediterranean Sea and the impact of Saharan dust events. Biogeosciences 8: 2773-2783.

Rodolfo-Metalpa, R., Hoogenboom, M.O., Rottier, C., Ramos-Esplá, A., Baker, A.C., Fine, M., and Ferrier-Pagès, C. (2014) Thermally tolerant corals have limited capacity to acclimatize to future warming. Glob. Chang. Biol. 20: 3036-3049.

Rodolfo-Metalpa, R., Reynaud, S., Allemand, D., and Ferrier-Pagès, C. (2008) Temporal and depth responses of two temperate corals, Cladocora caespitosa and Oculina patagonica, from the North Mediterranean Sea. Mar. Ecol. Prog. Ser. 369: 103-114.

Rodolfo-Metalpa, R., Richard, C., Allemand, D., Bianchi, C.N., Morri, C., and Ferrier-Pagès, C. (2006) Response of zooxanthellae in symbiosis with the Mediterranean corals Cladocora caespitosa and Oculina patagonica to elevated temperatures. Mar. Biol. 150: $45-55$.

Rognes, T., Flouri, T., Nichols, B., Quince, C., and Mahé, F. (2016) VSEARCH: a versatile open source tool for metagenomics. PeerJ 4: e2584.

Rubio-Portillo, E., Santos, F., Martínez-García, M., de los Ríos, A., Ascaso, C., SouzaEgipsy, V., et al. (2016) Structure and temporal dynamics of the bacterial communities 
associated to microhabitats of the coral Oculina patagonica. Environ. Microbiol. 18: $4564-4578$.

Rubio-Portillo, E., Vázquez-Luis, M., Valle, C., Izquierdo-Muñoz, A., and Ramos-Esplá, A.A. (2014) Growth and bleaching of the coral Oculina patagonica under different environmental conditions in the western Mediterranean Sea. Mar. Biol. 161: 2333-2343.

Rubio-Portillo, E., Yarza, P., Peñalver, C., Ramos-Esplá, A.A., and Antón, J. (2014) New insights into Oculina patagonica coral diseases and their associated Vibrio spp. communities. ISME J. 8: 1794-1807.

Sabeur, H., Wafa, F., Asma, H., and Malika, B. (2016) Long term characterization of Trichodesmium erythraeum blooms in Gabès Gulf (Tunisia). Cont. Shelf Res. 124: 95103.

Sangsawang, L., Casareto, B.E., Ohba, H., Vu, H.M., Meekaew, A., Suzuki, T., et al. (2017) ${ }^{13} \mathrm{C}$ and ${ }^{15} \mathrm{~N}$ assimilation and organic matter translocation by the endolithic community in the massive coral Porites lutea. R. Soc. Open Sci. 4: 171201.

Santos, H.F., Carmo, F.L., Duarte, G., Dini-Andreote, F., Castro, C.B., Rosado, A.S., et al. (2014) Climate change affects key nitrogen-fixing bacterial populations on coral reefs. ISME J. 8: 2272-2279.

Serrano, E., Ribes, M., and Coma, R. (2017) Recurrent partial mortality events in winter shape the dynamics of the zooxanthellate coral Oculina patagonica at high latitude in the Mediterranean. Coral Reefs 36: 27-38.

Shenkar, N., Fine, M., and Loya, Y. (2005) Size matters: bleaching dynamics of the coral Oculina patagonica. Mar. Ecol. Prog. Ser. 294: 181-188.

Stambler, N. (2011) Zooxanthellae: the yellow symbionts inside animals. In, Dubinsky,Z. and 
Stambler,N. (eds), Coral Reefs: An Ecosystem in Transition. Springer Netherlands, New York, pp. 87-106.

Szmant, A.M., Ferrer, L.M., and FitzGerald, L.M. (1990) Nitrogen excretion and O:N ratios in reef corals: evidence for conservation of nitrogen. Mar. Biol. 104: 119-127.

Tamura, K., Stecher, G., Peterson, D., Filipski, A., and Kumar, S. (2013) MEGA6: Molecular evolutionary genetics analysis version 6.0. Mol. Biol. Evol. 30: 2725-2729.

Tremblay, P., Peirano, A., and Ferrier-Pagès, C. (2011) Heterotrophy in the Mediterranean symbiotic coral Cladocora caespitosa: comparison with two other scleractinian species. Mar. Ecol. Prog. Ser. 422: 165-177.

Wijgerde, T., Diantari, R., Lewaru, M.W., Verreth, J.A.J., and Osinga, R. (2011) Extracoelenteric zooplankton feeding is a key mechanism of nutrient acquisition for the scleractinian coral Galaxea fascicularis. J. Exp. Biol. 214: 3351-3357.

Yang, Q., Dong, J., Zhang, Y., Ling, J., Wang, D., Wu, M., et al. (2015) Diversity analysis of diazotrophs associated with corals from Xisha and Sanya, South China Sea. Aquat. Ecosyst. Health Manag. 18: 433-442.

Yang, S.-H., Lee, S.T.M., Huang, C.-R., Tseng, C.-H., Chiang, P.-W., Chen, C.-P., et al. (2016) Prevalence of potential nitrogen-fixing, green sulfur bacteria in the skeleton of reef-building coral Isopora palifera. Limnol. Oceanogr. 61: 1078-1086.

Zehr, J., Waterbury, J.B., Turner, P.J., Montoya, J., Omoregie, E., Steward, G.F., et al. (2001) Unicellular cyanobacteria fix $\mathrm{N}_{2}$ in the subtropical North Pacific Ocean. Nature 412: $635-638$.

Zehr, J.P. and McReynolds, L.A. (1989) Use of degenerate oligonucleotides for amplification of the nifH gene from the marine cyanobacterium Trichodesmium thiebautii. Appl. 
Bednarz et al. Manuscript

Environ. Microbiol. 55: 2522-2526. 


\section{Table Legends}

Table 1. Summary of physiological key parameters $\left(P_{\mathrm{g}}\right.$ : gross photosynthesis, $R$ : respiration, Fv/Fm: photosynthetic efficiency) measured on healthy and bleached Oculina patagonica corals (mean \pm SE). $P$-values indicate significant differences $(t$-test, significance level $p<0.05$ ) for each parameter between the two coral conditions.

Table 2. Comparison of nitrogen uptake rates $\left(\mu \mathrm{g} \mathrm{N} \mathrm{cm}{ }^{-2} \mathrm{~d}^{-1}\right)$ by Oculina patagonica corals from diazotrophically-derived (DDN) as well as from different heterotrophic food sources and dissolved inorganic nitrogen (DIN) previously determined under in situ relevant concentrations. In situ uptake rates of microzooplankton, pico- and nanoplankton and detrital particulate organic matter (DPOM) represent values measured for $O$. patagonica corals (Tremblay et al., 2011) and considering 80\% carbon assimilation efficiency (Anthony, 2000). DIN uptake rates (i.e. ammonium) were measured for tropical corals (Grover et al., 2002) due to the lack of similar measurements for Mediterranean corals and were considered at ambient DIN concentrations of $0.2 \mu \mathrm{M}$ representative for the oligotrophic Mediterranean Sea.

\section{Table 1.}

\begin{tabular}{|c|c|c|c|}
\hline Physiological parameters & Healthy & Bleached & $p$-value \\
\hline Symbiodinium content $\left(\mathrm{mg} \mathrm{cm}^{-2}\right)$ & $9.4 \pm 2.4$ & $3.1 \pm 0.6$ & 0.009 \\
\hline$F v / F m$ & $0.61 \pm 0.07$ & $0.60 \pm 0.03$ & 0.660 \\
\hline$P_{\mathrm{g}}\left(\mu \mathrm{g} \mathrm{O} \mathrm{cm}^{-2} \mathrm{~h}^{-1}\right)$ & $38.8 \pm 5.3$ & $25.9 \pm 3.1$ & 0.190 \\
\hline$R\left(\mu \mathrm{g} \mathrm{O} \mathrm{cm}^{-2} \mathrm{~h}^{-1}\right)$ & $-15.8 \pm 2.1$ & $-21.6 \pm 2.8$ & 0.060 \\
\hline Grazing rates (Nauplii $\mathrm{cm}^{-2} \mathrm{~h}^{-1}$ ) & $368 \pm 77$ & $384 \pm 53$ & 0.868 \\
\hline
\end{tabular}

Table 2.

\begin{tabular}{|c|c|c|}
\hline Nitrogen source & 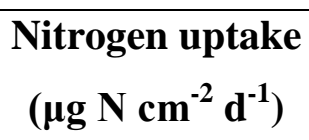 & Reference \\
\hline DDN (healthy corals) & $0.06-0.16$ & Present study \\
\hline DDN (bleached corals) & $0.22-0.35$ & Present study \\
\hline
\end{tabular}




\begin{tabular}{|l|c|c|}
\hline Microzooplankton & 5.36 & Tremblay et al., 2011 \\
\hline Pico-and nanoplankton & 1.54 & Tremblay et al., 2011 \\
\hline DPOM & 0.28 & Tremblay et al., 2011 \\
\hline DIN & 0.72 & Grover et al., 2002 \\
\hline
\end{tabular}

\section{Figure Legends}

Figure 1. Overview of the composition of the overall bacterial community (A) and the diazotrophic community (B) associated with the tissue and mucus of Oculina patagonica and with the surrounding seawater. No nifH sequences were recovered from the seawater. The relative abundance of each taxon within the community is indicated in percentages (\%). The contribution of taxa to the overall and diazotrophic community is presented at the order and class level, respectively.

Figure 2. Phylogeny of the nifH operational protein units (OPU) recovered from Oculina patagonica. Reconstruction of the maximum-likelihood phylogenetic tree was based on the nifH sequences using the Whelan and Goldman (WAG) model. The 24 newly identified nifH OPUs from O. patagonica are denoted as "MED" including the protein accession numbers and boot strap support $>70 \%$ is indicated on applicable nodes.

Figure 3. Total and compartment-specific assimilation of diazotrophically-derived nitrogen (DDN) in healthy and bleached Oculina patagonica corals. Assimilation rates are normalized to the skeletal surface area of the colony (mean $\pm \mathrm{SE})$. Asterisks indicate a significant difference of the total assimilation between the two coral conditions (healthy vs bleached) based on individual Student's t-tests (significance level, $* *<0.005)$. Different letters (A-F) indicate significant differences of DDN assimilation between coral compartments and conditions based on two-factor permutational ANOVA with pairwise Monte Carlo tests (significance level, $\mathrm{p}<0.05$ ). 
Figure 4. Compartment-specific assimilation of diazotrophically-derived nitrogen (DDN) in healthy and bleached Oculina patagonica corals. Assimilation rates are normalized to the dry weight of the corresponding compartment $($ mean \pm SE). Asterisks indicate a significant difference of the assimilation between healthy and bleached corals based on individual Student's t-tests (significance level, $* * *<0.001$ ).

Figure 5. Conceptual model about the potential role of diazotrophs for the temperate coral Oculina patagonica during bleaching. Coral bleaching (i.e. loss of Symbiodinium) can induce carbon $(\mathrm{C})$ and nitrogen $(\mathrm{N})$ shortages for the coral host due to a disrupted nutrient recycling and a reduced translocation of photosynthates. An increased activity of the diazotrophic community (dominated by autotrophic diazotrophs) under elevated temperature can provide an alternative source of photosynthetic $\mathrm{C}$ and $\mathrm{N}$ (i.e. diazotrophically-derived nitrogen; DDN) for the coral host. In addition, DDN together with the increased light levels reaching the skeleton in bleached corals may stimulate the growth of photosynthesizing endolithic algae, which also represent an alternative $\mathrm{C}$ source for the coral host. Thus, we hypothesize that diazotrophs can positively affect bleached $O$. patagonica corals both directly (i.e. substituting $\mathrm{C}$ and $\mathrm{N}$ acquisition of the coral host) and indirectly (i.e. stimulating endolithic algae growth that substitutes $\mathrm{C}$ acquisition of the coral host), thereby contributing to the high survival and recovery rate of this coral species from annual bleaching events. 

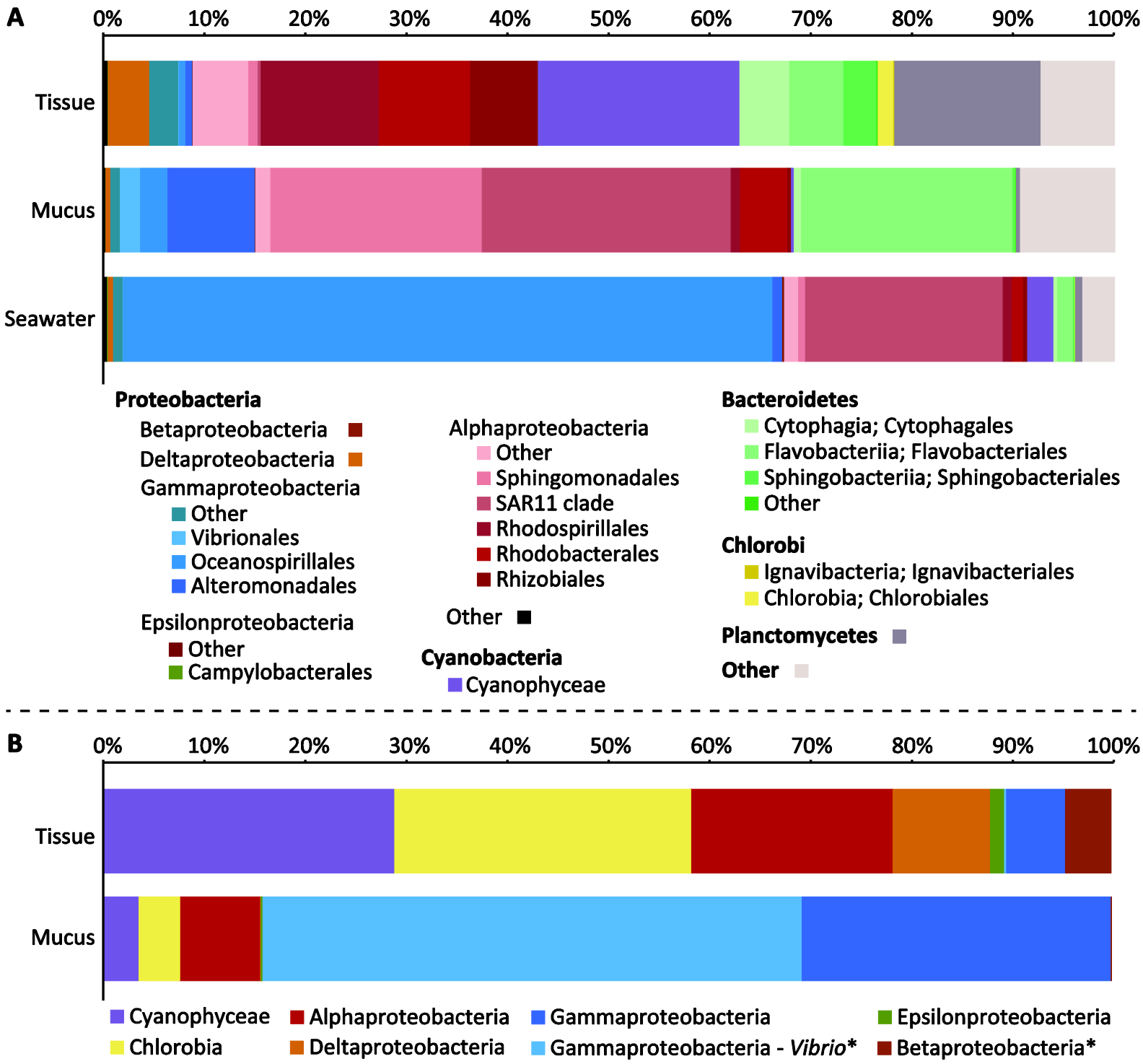


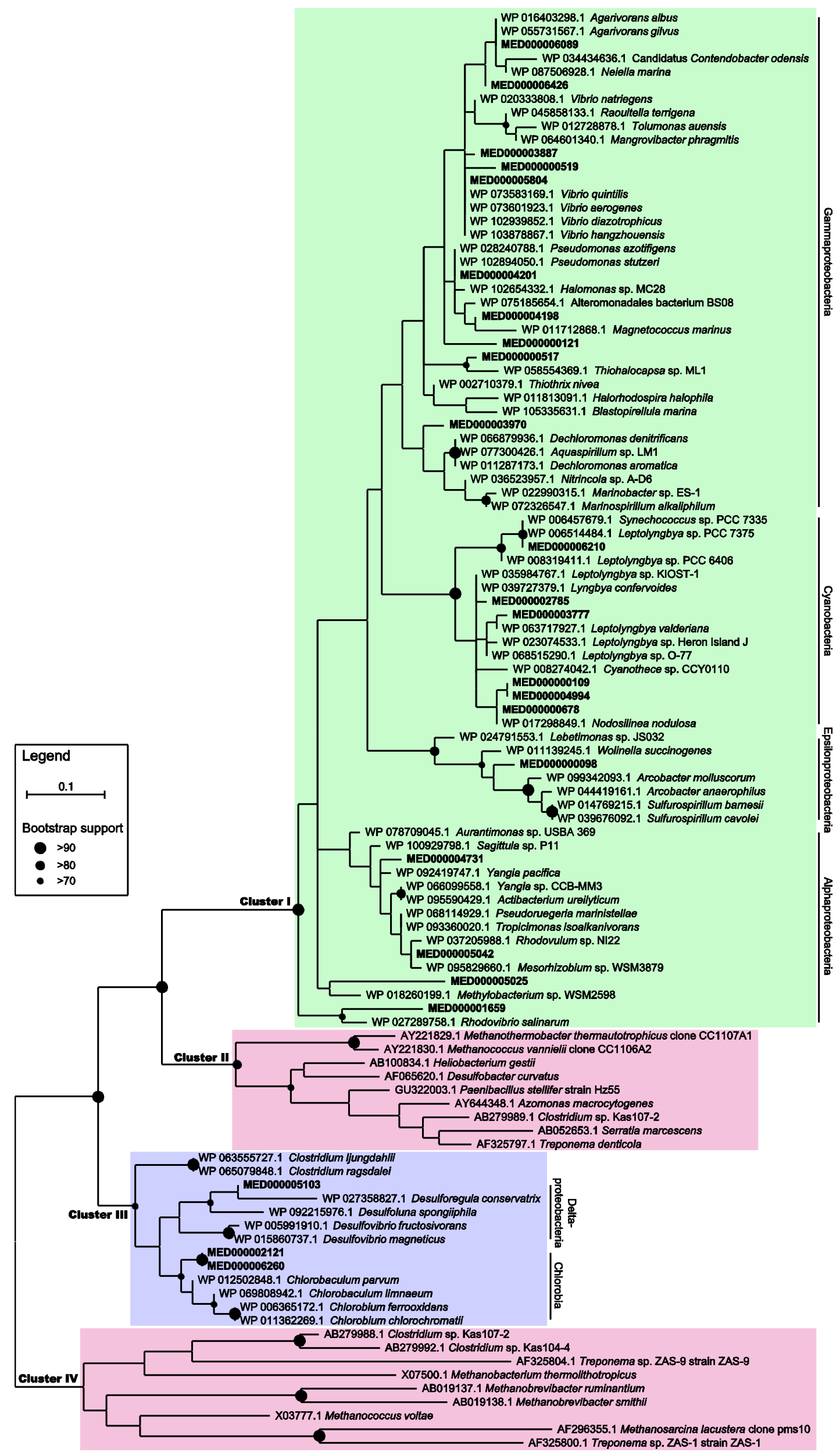



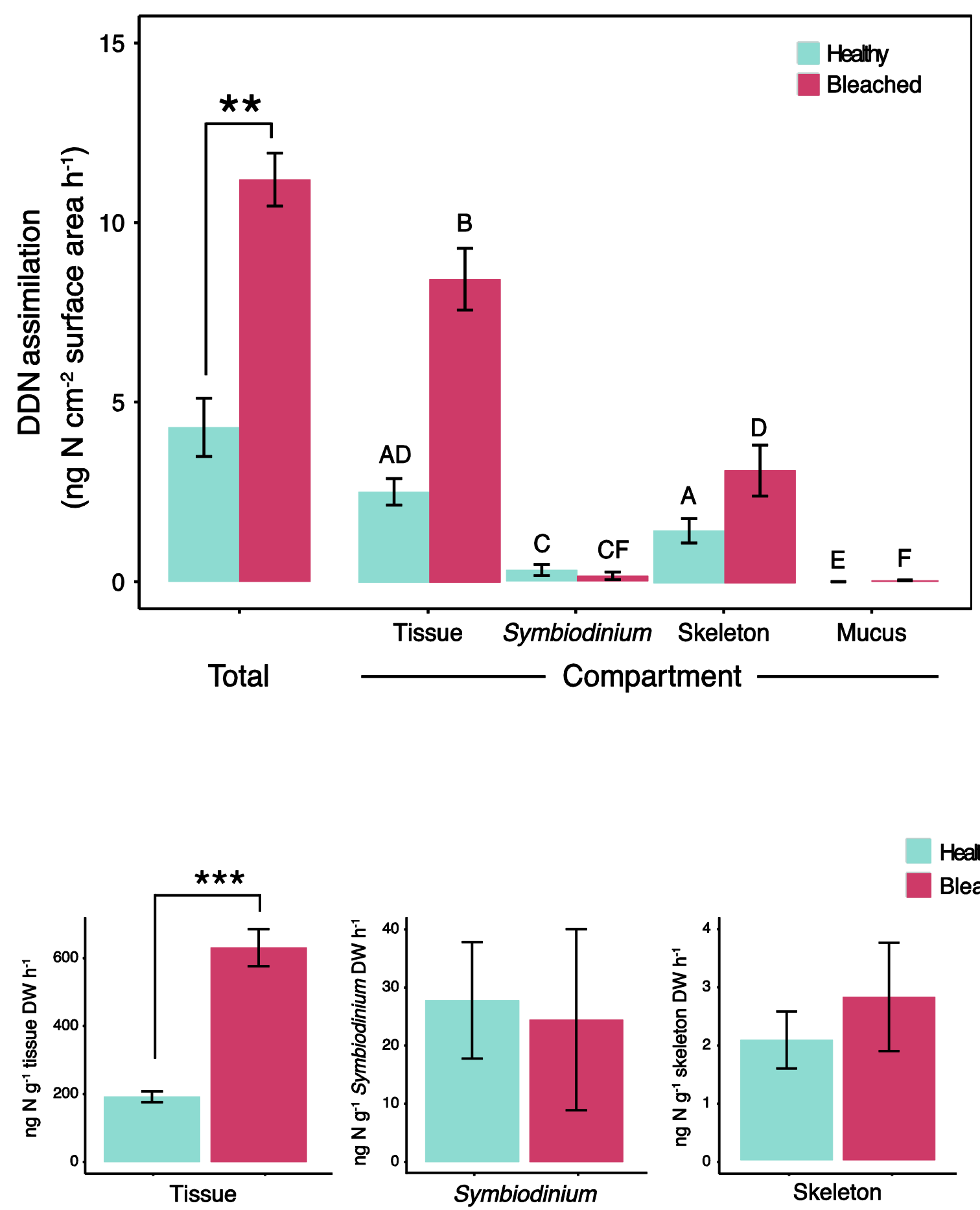

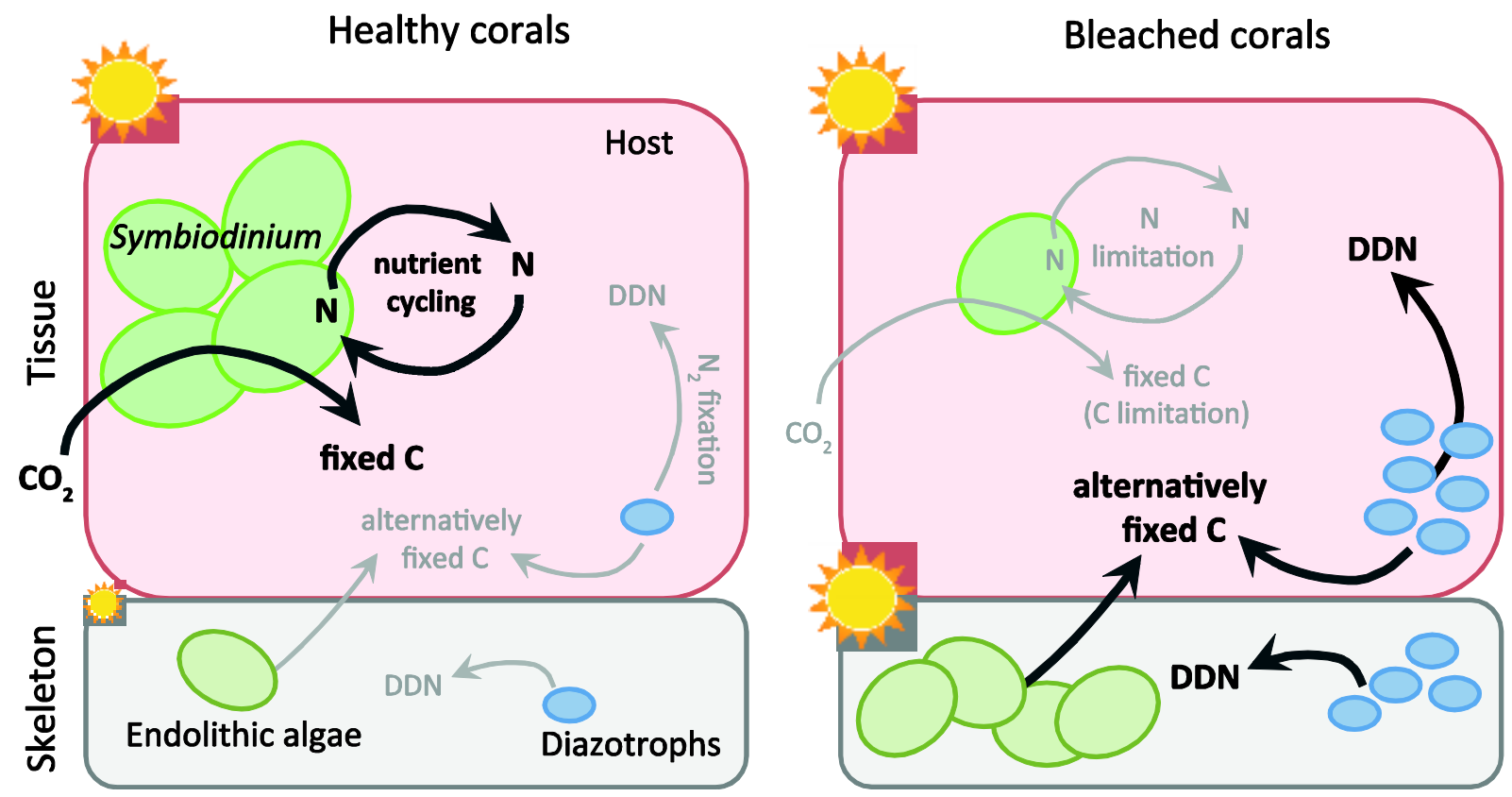